\title{
Mass mortality of abalone Haliotis cracherodii on the California Channel Islands: tests of epidemiological hypotheses
}

\author{
Kevin D. Lafferty, Armand M. Kuris \\ Department of Biological Sciences and Marine Science Institute, University of California, Santa Barbara, Santa Barbara, \\ California 93106, USA
}

\begin{abstract}
Along the coast of the California Channel Islands, USA, the abundant black abalone Haliotis cracherodii began to die in large numbers in 1985. This die-off has spread to most of the islands and still continues. Analysis of the changes in abalone abundance at numerous locations suggests that this is the result of an infectious disease spreading slowly from the south side of Santa Cruz Island. However, this might not be due to a directly transmitted disease and we have found no agent of infection. As with many diseases, warm temperatures acted to increase mortality rates. Our results were not consistent with other hypotheses for the decline such as over-harvesting, pollution, or factors related to physiological stresses induced by the strong El Nino of $1983-84$, including warm temperatures, starvation and competition.
\end{abstract}

\section{INTRODUCTION}

Mass mortalities of marine organisms are infrequent but important phenomena (Williams \& BunkleyWilliams 1990). When an abundant organism rapidly and completely disappears from a region, the community structure and its organizational dynamics may undergo dramatic changes. These mass mortalities may start ecological processes leading to the type of alternative stable states recognized by Sutherland (1974). If the species undergoing such a crash had previously sustained a fishery, or was valuable for other considerations, the mass mortality assumes even greater importance for human affairs.

Some examples of mass marine mortalities include: the loss of eelgrass Zostera marina beds to wasting disease in the 1930 s along the Atlantic shore of the United States (DenHartog 1987), the devastation of vast areas of oyster Crassostrea virginica beds due to Perkinsus marinus infection in mid-Atlantic estuaries of the United States (Perkins 1976), the crash of sea urchin Strongylocentrotus droebachiensis populations on the eastern coast of North America in the 1980 s (Miller \&
Colodey 1983) caused by an amoeba (Jones \& Scheibling 1985) and of $S$. franciscanus along the California coast in the 1970 s (Pearse et al. 1977) also caused by an infectious disease, the spectacular decline in Diadema antillarium populations in the Caribbean region in the 1980 s (Lessios 1988) and the near elimination of the starfish Heliaster kubiniji in the Sea of Cortez in the 1970 s caused by infectious agents (Dungan et al. 1982). For these events, population declines were both rapid and widespread and the causative agent often remained unknown. These circumstances have prevented the careful analysis of the geographic pattern of these mass mortalities, as biologists generally became aware of them after the event was nearly over and, usually, lacked background data to document the spread and extent of the population decline.

Long-term changes in the abundance of black abalone Haliotis cracherodii on the California Channel Islands (USA) reflect historical events. Evidence from Indian middens (Cox 1962, Muratto 1984) shows that Native Americans heavily fished the abundant black abalone populations. In the early 1800s, the removal of 
the human population (Johnson 1982, Douros 1985) and the extirpation of sea otter populations by Russian fur hunters (VanBlaricom \& Estes 1988) virtually eliminated vertebrate predatory pressure on black abalone populations. Other abalone predators, such as the California sheephead and the spiny lobster, have also declined (Tegner 1980, Tegner \& Levin 1983). As a result, throughout the twentieth century, black abalone attained high population levels on the Channel Islands and became one of the most abundant large invertebrates in the middle and lower rocky intertidal zones (Douros 1985). Indeed, it was typical to observe 3 or 4 black abalone stacked on each other (Cox 1960, Douros 1987). Since 1973, black abalone populations in the Channel Islands have supported a substantial commercial export fishery (Parker et al. 1992).

In 1985, commercial fishermen observed large numbers of empty shells and dying abalone on the southern shore of Santa Cruz Island. Similar die-offs subsequently happened on Anacapa, Santa Rosa, Santa Barbara, San Miguel, and San Clemente islands and, recently (summer of 1992), on San Nicolas Island (Fig. 1) (Haaker et al. 1992). There are no quantitative observations for Santa Catalina, nor for Islas Coronados in Mexico. A similar pattern occurred at
Diablo Cove (Steinbeck et al. 1992) but not at other mainland locations where long-term observations have been available (Point Loma and the Palos Verdes Peninsula).

Shepherd \& Breen (1992) discuss a variety of factors responsible for past abalone mortalities in California and elsewhere. Sometimes, it appears that human factors were responsible. Coastal development, harvesting and pollution have depleted coastal stocks in California (Haaker et al. 1986, Tegner 1989). In particular, Young (1964) implicated sewer effluent at White's Point, Palos Verdes, for a shrunken foot condition there. Copper discharged from the cooling system of Diablo Canyon Nuclear Power Plant resulted in heavy mortality to the adjacent population (Martin et al. 1977). Natural events also cause mortality. Storms can result in abalone being crushed or torn off of the substrate (Cox 1962, Sainsbury 1982, Tegner \& Butler 1989). In Australia, dinoflagellate blooms ( $R$. Tarr in Shepherd \& Breen 1992) and the protozoan Perkinsus olseni are linked with high mortality (Lester et al. 1988, O'Donoghue et al. 1991). In several locations, starvation, due to the reduced availability of drift algae, has also been documented (Ino 1966, Sakai 1962, Schmitt \& Connell 1984, Tanaka et al. 1986).
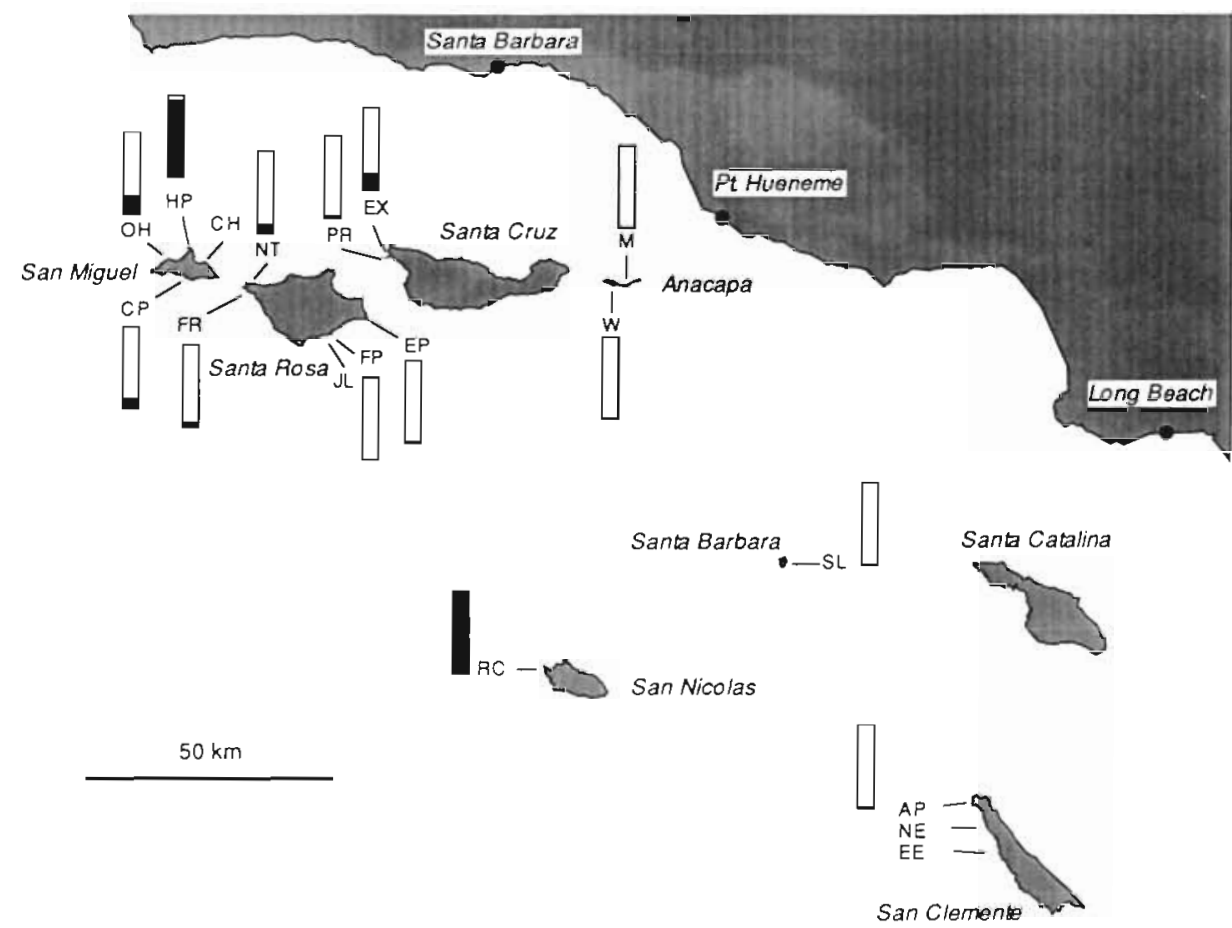

Fig. 1 Channel Islands off the coast of southern California, showing the sites where abalone Haliotis cracherodii populations were monitored. $\mathrm{AP}=$ Airport. $\mathrm{CH}=$ Cuyler Harbor, $\mathrm{CP}=$ Crook Pt, $\mathrm{EE}=\mathrm{Eel} \mathrm{Pt}$., $\mathrm{EP}=$ East Pt., EX $=$ Exposed, $\mathrm{FP}=\mathrm{Ford}$ Pt., FR $=$ Fossil Reef, $\mathrm{HP}=$ Harris Pt., JL $=$ Johnson's Lee, $\mathrm{M}=$ Middle, NE $=$ North Eel Pt., NT $=$ North West Talcott, $\mathrm{OH}=\mathrm{Otter}$ Har bor, $\mathrm{PR}=$ Protected, $\mathrm{RC}=$ Rock Crusher, $\mathrm{SL}=$ Sea Lion, $\mathrm{W}=$ West. The solid part of each bar represents the remaining proportion (1991) of the initial population at each site 
Although the pattern of declining fisheries landings suggests over-harvesting (Parker et al. 1992), there is an association between mortalities in the Channel Islands and a set of morphological conditions termed withering syndrome (WS) for which the most striking feature is a withered foot. Only a quick and stealthy tug can remove a healthy abalone. However, weakened abalone in late stages of the disease readily detach from the substrate. A weakened foot is not diagnostic for WS because a withered foot is a common terminal symptom of several abalone diseases. Other aspects of WS include color changes of the foot and epipodium and reduced gonadal size (Haaker et al. 1992, Kuris et al. unpubl.). Sites suffering from WS have abnormally high numbers of fresh, empty shells from all sizes of recently dead individuals (Haaker et al. 1992). These observations indicate that declines in abalone densities are, at least partially, independent of the commercial or sport fishery, and may be attributable to WS (because landed abalone must be of legal size and have an intact shell).

Although the cause of WS has been elusive, there are a number of proposed hypotheses. While the most complicated hypothesis involves 16 interacting causal factors (Davis et al. 1992), the only explicitly tested hypothesis is that a recently discovered, as yet undescribed, coccidian protozoan associated with kidney damage causes WS (Steinbeck et al. 1992). Rejection of this infectious agent as the cause of WS stems from the observation that it is present in all of the black abalone sampled (it may be present at higher intensities in healthy animals than in sick animals), and there is no association between coccidian intensity and increased WS pathology (Steinbeck et al. 1992, Friedman unpubl., Kuris \& Stevens unpubl.). However, at high intensities, gonad and right kidney weights were low (Kuris \& Stevens unpubl.).

Compared to other marine mass mortalities, the present episode provides some unique opportunities for study. The crash of black abalone populations has occurred over a long time ( $7 \mathrm{yr}$ and still ongoing). Also, several jurisdictional agencies (California Department of Fish \& Game, Channel Islands National Park, U.S. Fish \& Wildlife Services, Pacific Gas \& Electric Co.) monitor the region in which it occurred for a variety of purposes. Thus, this mass mortality had considerable prior background data and occurred slowly enough to permit study of its epidemiology.

\section{APPROACH}

Our objective was to determine what factors led to the epidemic. To separate mortality due to the fishery from losses due to WS, we concentrated our efforts on changes in the density of sub-legal individuals $(<14.6 \mathrm{~cm})$. This indicates fishery-independent mortality. It was also necessary to determine associations between the activities of the fishery and the dieoff associated with WS. To test the hypothesis that the fishery is the cause of the mass mortality, we examined the relationship between fishing pressure and sublegal abalone density at many locations throughout the Channel Islands. If the fishery was indirectly responsible for the die-off, we predicted a negative association between fishing intensity and changes in sub-legal abalone density. Further, if WS is an entity spread by human activities we expected that heavily fished areas, or those close to major ports, would become affected at early dates.

Some evidence suggests that El Niño periods with warm water temperatures were the initial cause of WS and the resultant mortality (Tissot 1988, 1990, Davis et al. 1992). A variant of this hypothesis is that because El Niño events reduce kelp abundance (Tegner \& Dayton 1987), and drift kelp is the main food source of black abalone (Cox 1962, Leighton \& Boolootian 1963, Douros 1987), black abalone may have starved to death (Tissot 1988, 1990). Evidence in support of the El Nino hypothesis includes: (1) the die-offs began soon after the strong El Niño of 1983-84, (2) in 1988, mortality occurred in association with warm water discharged from Diablo Canyon Nuclear Power Plant (Steinbeck et al. 1992), and (3) abalone at Año Nuevo, presumably north of the influence of El Niño, did not suffer from WS (Tissot 1988). However, the occurrence of WS after El Niño could have been happenstance and warm water may not have been the sole causal factor at Diablo Canyon since mortality did not occur in previous years with similar or warmer temperatures (Steinbeck et al. 1992).

We conducted a multi-site geographic analysis to test the observations of Tissot $(1988,1990)$. Three predictions arise from the hypothesis that El Niño was responsible for WS. We expected an association between the initiation of WS die-offs and periods of warmer than average water temperature. We also predicted a positive association between changes in abalone and kelp densities because warm water reduces kelp abundance and black abalone feed on kelp. Because sea urchins are a potential competitor for drift kelp (Tegner \& Levin 1982) and foraged aggressively after El Niño (Ebeling et al. 1985), we predicted a negative association between changes in abalone and urchin densities. We examined these relationships for potential time lags as the El Niño might have a delayed effect on abalone survivorship.

Two other causal hypotheses are that mortality was due to a pollutant or an infectious disease agent. Unlike the fisheries or the El Niño/starvation hypothe- 
ses, in which there is an established causal chain of events, the pollution and infectious disease hypotheses both rely on undiscovered agents. The gradual spread of WS from a central focus would be consistent with either an infectious process or the spread of a pollutant. Both of these possible causes would be supported by evidence that WS appears sooner in locations downstream of the prevailing currents than at upcurrent sites. Davis et al. (1992) suggest the abnormally high densities of black abalone led to stresses that triggered the mass mortality. If WS was a directly transmitted disease, we expected that areas with initial high population densities would suffer higher mortality rates. On the other hand, because a pollutant would tend to become diluted far from its source, we would expect mortality rates to decline at more distant locations if a pollutant rather than an infectious disease was the causative agent of WS.

\section{METHODS}

We used a correlational approach to determine if the spread of the epidemic was consistent with predictions stemming from the proposed hypotheses. We were able, in several cases, to compare the observed patterns with results of a more experimental nature. We first collected the available information on black abalone in the Channel Islands. Marine biologists associated with the Channel Islands National Park (CINP), California Department of Fish and Game, U.S. Fish and Wildlife Service and Oregon State University generously provided abalone population data and other helpful information. This information included biannual population surveys conducted by the Rocky Intertidal Communities Monitoring Program (Haaker et al. 1992) and data on kelp and sea urchin abundance. from the Kelp Forest Monitoring Program (Davis et al. 1992), both of the CINP. Biologists from the California Department of Fish and Game, Pacific Gas and Electric Company, and several commercial fishermen provided additional observations on WS.

Most populations in which WS was evident exhibited a decline in density over time that fit a form of the logistic curve. To estimate the rate at which WS spread through the monitored abalone populations and the date that it first affected density, we expressed the size frequency distribution for sub-legal sized abalone at each site as a relative frequency distribution. Then, using least squares methods, we fitted each relative frequency distribution to the following derived form of the logistic equation:

$$
N_{0}-N_{t}=\frac{N_{0}}{1+e^{d-r t}}
$$

where $N_{0}=$ the initial population size; $N_{1}=$ the population size at time $t_{i}$ and $a$ is a constant. The parameter $r$ of the logistic equation represents the intrinsic rate of change of a population. We used this value as an index of the mortality rate of each population and used the date at which the mortality reached $10 \%$ of the initial population as the date of initiation of the die-off at each site. For regularly visited populations where density data were not available, we recorded the date at which WS was first noted as the start of the die-off (California Department of Fish and Game, Marine Resources Division Nearshore Invertebrate Project Field Reports).

Monthly fishing intensity for each site was estimated by using reported landings of the black abalone fishery compiled by the California Department of Fish and Game. Fishermen report landings according to a numbered grid of blocks published as the 'Southern California Fisheries Chart'. Each block represents a square area of 10 minutes of latitude by 10 minutes of longitude. Because each block covers a large area, more than one site was occasionally within a block. To examine the relationship between fishing intensity and WS, we calculated the correlation (Pearson) between the proportional change in sub-legal abalone density and the tonnes of abalone landed for each site where such data were both available.

We obtained sea water temperatures at each site from the field notes of the biologists that conducted the abalone monitoring. In addition, to estimate regional effects of El Niño, we used a long-term record of daily sea water temperature collected at the University of California, Santa Barbara. Taking the average temperature record of each day of the year, over $10 \mathrm{yr}$, generated a seasonal average. This way it was possible to determine whether the temperature was unseasonably warm or cold during a particular die-off event. We determined the mean and $95 \%$ confidence limits for sea water temperatures recorded during die-offs. We then compared this with the 10 yr mean sea water temperature and the seasonally adjusted temperature for that date.

The Kelp Forest Monitoring Project of CINP provided anmual data on kelp density as presented in Davis et al. (1992). In short, these represent the total number of adult plants ( $>1 \mathrm{~m}$ high) per $\mathrm{m}^{2}$ along a fixed transect. Although these data do not quantify drift kelp, it is likely that there is a correlation between drift kelp and kelp density over the time scale sampled. Data on sea urchins were collected in a similar manner to the data on kelp density. We only used information from kelp forest sites that were near intertidal abalone sites. To examine the association of these variables with WS, we calculated the correlation between the proportional change in sub-legal abalone density and the proportional change in kelp or urchin density. 
In our geographic analysis, we investigated the association of the timing and rate of the die-offs with the distance of each site from the initial observation of WS (south side of Santa Cruz Island). Ocean distance measures between each site and the south side of Santa Cruz Island or the nearest port were obtained by applying mapping software to scanned charts. For each site, we examined these distances and the rate of the die-off for correlations with die-off date.

Ocean circulation maps (Resources Partnership 1974, Hendershott 1991) indicated that the prevailing currents were from the northeast but that seasonal variation allowed for occasional back-flow from the southwest. This back-flow indicated dispersal of an infectious agent or pollution was possible anywhere within the Southern California Bight but that transport to the northwest was less likely than transport to the southeast. We assumed that sites up-current (northwest) of the south side of Santa Cruz Island were, in effect, further removed from this location than sites that were down-current (southeast). To determine the 'current-adjusted' distance of sites up-current from the south side of Santa Cruz Island, we multiplied up- current ocean distances by a 'resistance' factor. We varied this resistance factor from 1 (no resistance) to 2 (heavy resistance) and then calculated the correlation coefficients associated with the date of each die-off and the distance from the south side of Santa Cruz. We predicted that if currents were important for the spread of WS, the association between die-offs and distance from the initial site would be stronger for levels of resistance greater than 1.

\section{RESULTS}

The available data on abalone densities, mortality rates, temperature, distances from the south side of Santa Cruz Island and the nearest ports, and landings for 18 sites on 7 Channel Islands are summarized in Table 1. Fishing mortality dissipated following declines in abalone density. There was no association between fishing intensity and changes in sub-legal abalone density whether measured at each site or for all sites and times pooled $(r=-0.074, \mathrm{df}=65, \mathrm{p}>0.05)$. The WS-associated mortality began at various sites on

Table 1. Date of initiation of die-off, initial black abalone Haliotis cracherodii density, mortality rate, water temperature, distances from the south side of Santa Cruz Island and the nearest port, and landings for each site in the California Channel Islands where abalone densities were available. Dates of the initiation of the die-off were estimated as a $10 \%$ decline in density or as observed in the field. Fishery landings represent 12 yr (1980 to 1991) sums by block number each site is in. Sea water temperatures shown are: (1) 10 yr UCSB (Univ. of California. Santa Barbara) average for each date of die-off, (2) temperature at UCSB for date of dieoff, or (3) temperature obtained at the site near peak of die-oft. Mortality rate was estimated as the logistic parameter $r$. Distance, in kilometers, of each site is shown from (1) the initial location of the die-off (south side of Santa Cruz Island), (2) the initial location of the dje-off factored for resistance against prevailing currents, and (3) the nearest port (Santa Barbara, Port Hueneme, or Long Beach). Initial, pre-die-off density is given as no. of individuals per $\mathrm{m}^{2}$ of fixed transect. Islands: ANA = Anacapa Island, $\mathrm{SBA}=$ Santa Barbara Island, $\mathrm{SCL}=$ San Clemente Island, $\mathrm{SCR}=$ Santa Cruz Island, $\mathrm{SMI}=$ San Miguel Island, SNI = San Nicolas Island, $\mathrm{SRO}=$ Santa Rosa Island. Site abbreviations as in Fig. 1. -: no records

\begin{tabular}{|c|c|c|c|c|c|c|c|c|c|c|c|}
\hline \multirow[t]{2}{*}{ Island } & \multirow[t]{2}{*}{ Site } & \multirow{2}{*}{$\begin{array}{c}\text { Die-off } \\
\text { date }\end{array}$} & \multirow{2}{*}{$\begin{array}{l}\text { Landings } \\
\quad \text { (t) }\end{array}$} & \multicolumn{3}{|c|}{ Temperature $\left({ }^{\circ} \mathrm{C}\right)$} & \multirow{2}{*}{$\begin{array}{c}\text { Mortality, } \\
r\end{array}$} & \multicolumn{3}{|c|}{$\mathrm{km}$ from die-off start } & \multirow{2}{*}{$\begin{array}{l}\text { Initial } \\
\text { no. } \mathrm{m}^{-2}\end{array}$} \\
\hline & & & & $\begin{array}{l}\text { UCSB } \\
\text { mean }\end{array}$ & $\begin{array}{l}\text { UCSB } \\
\text { on date }\end{array}$ & $\begin{array}{c}\text { At } \\
\text { site }\end{array}$ & & $\begin{array}{l}\text { From } \\
\text { start }\end{array}$ & $\begin{array}{l}\text { With } 1.5 \\
\text { current }\end{array}$ & $\begin{array}{l}\text { From } \\
\text { port }\end{array}$ & \\
\hline ANA & M & Feb 1986 & 0.8 & 14.0 & 13.9 & 13.8 & 2.13 & 24.7 & 24.7 & 22.3 & 70 \\
\hline ANA & W & Aug 1986 & 0.8 & 18.0 & 16.7 & 17.1 & 2.18 & 22.3 & 22.3 & 25.9 & 26 \\
\hline SBA & SL & Jun 1988 & 3.7 & 17.4 & 17.3 & 16.7 & 24.0 & 79.9 & 80.0 & 74.1 & 5.4 \\
\hline$S C L$ & $\mathrm{AP}$ & Jun 1990 & 2.3 & 17.4 & 18.3 & - & - & 143 & 143.0 & 94.1 & - \\
\hline $\mathrm{SCL}$ & $\mathrm{EE}$ & Jun 1990 & 68 & 17.4 & 18.3 & - & - & 64.7 & 149.0 & 100 & - \\
\hline SCL & $\mathrm{NE}$ & Jun 1990 & 68 & 17.4 & 18.3 & - & - & 149 & 155.0 & 107 & - \\
\hline SCR & $E X$ & Jul 1987 & 0.9 & 17.7 & 16.7 & 16.3 & 2.31 & 31.7 & 50.8 & 45.9 & 37 \\
\hline SCR & PR & Mar 1987 & 0.9 & 14.4 & 14.3 & 15.7 & 3.59 & 31.7 & 50.8 & 45.9 & 50 \\
\hline SMI & $\mathrm{CH}$ & Jun 1990 & 163 & 17.4 & 18.3 & - & - & 155 & 103.0 & 72.9 & - \\
\hline SMI & $C P$ & Jun 1990 & 163 & 17.4 & 18.3 & 13.9 & 0.65 & 68.2 & 109.0 & 81.1 & 41 \\
\hline SMI & $\mathrm{HP}$ & Jul 1990 & 163 & 17.7 & 18.7 & - & - & 68.2 & 109.0 & 74.1 & 14 \\
\hline SMI & $\mathrm{OH}$ & Nov 1988 & 163 & 15.0 & 13.1 & - & - & 72.9 & 117.0 & 78.8 & 26 \\
\hline SNI & $\mathrm{RC}$ & Mar 1992 & 86 & 14.4 & 17.4 & - & - & 77.6 & 77.6 & 101 & - \\
\hline SRO & EP & Jun 1988 & 2.3 & 17.4 & 17.3 & 18.0 & 24.2 & 29.4 & 47.0 & 58.8 & 1.1 \\
\hline SRO & FP & Jul 1986 & 3.5 & 17.7 & 15.2 & 14.4 & 1.55 & 37.6 & 60.2 & 67.0 & 23 \\
\hline SRO & $\mathrm{FR}$ & Jan 1989 & 1.9 & 14.0 & 13.4 & - & 2.43 & 61.1 & 97.8 & 75.3 & 25 \\
\hline SRO & $\mathrm{JL}$ & Jul 1986 & 3.5 & 17.7 & 15.2 & 14.4 & 1.56 & 40.0 & 64.0 & 70.6 & 42 \\
\hline SRO & NT & Aug 1988 & 43 & 18.0 & 16.1 & 14.0 & 1.36 & 57.6 & 92.2 & 67.0 & 12 \\
\hline
\end{tabular}




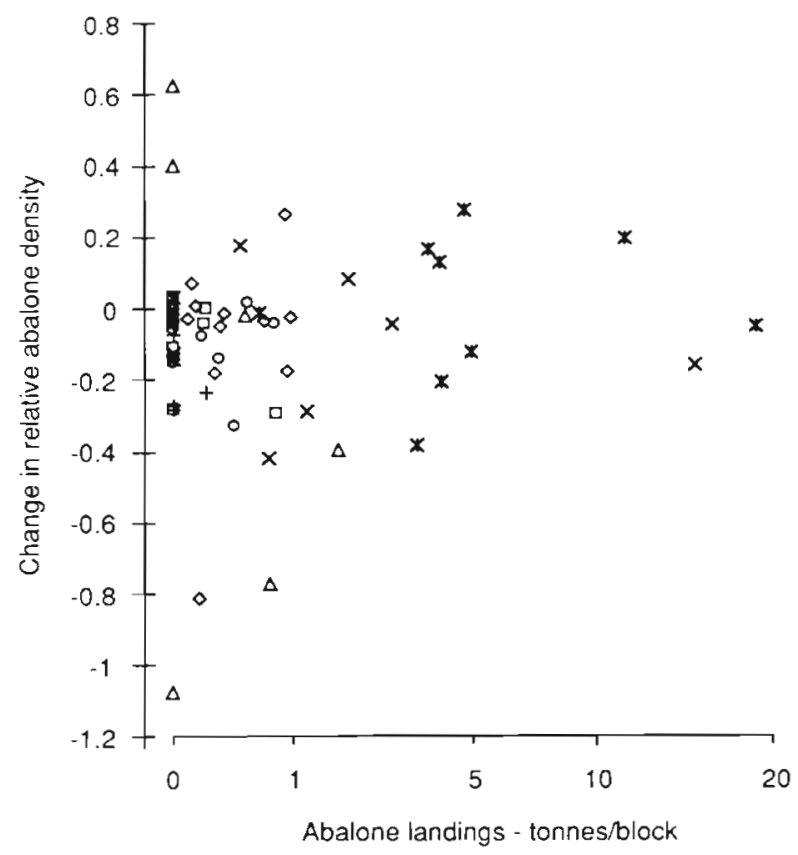

Fig. 2. Haliotis cracherodii. Changes in abalone density at 7 sites and the level of harvesting that occurred at each location for the same time period. Points represent biannual samples. (ㅁ) $\mathrm{M}_{1}(\infty) \mathrm{SBA},(\Delta) \mathrm{EP},(0) \mathrm{FP},(\times) \mathrm{NT},(+) \mathrm{FR},(*) \mathrm{OH}$ (site abbreviations as in Fig. 1)

different dates and proceeded at different rates. Contrary to the over-harvesting hypothesis, die-offs occurred later at heavily fished areas (Fig. 2; $\mathrm{r}=0.282$, $\mathrm{df}=70, \mathrm{p}<0.05$ ). There was also no relationship between the dates of die-offs and the distance of each site to the closest port ( $\mathrm{r}=$ $0.040, \mathrm{df}=16, \mathrm{p}>0.05$ ).

We found that the die-offs occurred, on average, during warmer periods $\left(16.5 \pm 0.8^{\circ} \mathrm{C}\right.$, $95 \% 2$-tailed confidence interval) than the 10 yr mean sea water temperature $\left(15.9^{\circ} \mathrm{C}\right)$. This difference was significant for the 1 -tailed prediction that warm water is associated with the die-off. However, when we adjusted these values for seasonality, we found that die-offs occurred at $0.05 \pm 0.7^{\circ} \mathrm{C}$ below the seasonal average. In other words, die-offs were not associated with warm years or El Niño events. There was, however, an association between water temperatures and mortality rates. Die-offs proceeded more rapidly in warm than cold instances $(r=0.77$, $\mathrm{df}=7, \mathrm{p}<0.01)$. Overall, there was no relationship between changes in abalone density and changes in kelp density (Fig. $3 ; r=0.051$, $\mathrm{df}=21, \mathrm{p}>0.05$ ) and no significant association between changes in abalone and sea urchin densities to indicate competition for resources was responsible for changes in abalone density (Fig $4 ; \mathrm{r}=-0.236$, $\mathrm{df}=21, \mathrm{p}>0.05$ ). Abalone density changes were not associated with changes in kelp or urchin abundance even when we incorporated time lags (i.e. the correlation coefficient was not significant for 1 to 4 yr temporal delays between urchin or kelp density and changes in abalone density). A non-significant association was found for all sites analyzed individually except Crook Pt. (CP), where there was a significant positive association between changes in kelp and abalone abundance $(\mathrm{r}=0.897, \mathrm{df}=3, \mathrm{p}=0.04)$. The other 3 sites (W, JL, NT) had non-significant negative associations between kelp and abalone.

Withering syndrome has spread over the past several years (Fig. 5). As previously mentioned, WS was first observed and presumably started on the south side of Santa Cruz Island around 1985 (unpubl. obs. of commercial abalone fishermen). By 1986, WS spread east to Anacapa Island and west to the south side of Santa Rosa Island. In 1987, WS reached the northwest sides of Santa Cruz Island. Santa Rosa Island and Santa Barbara Island to the southeast were impacted in 1988. By 1990, many areas on San Miguel Island had diseased abalone and a massive die-off was underway at San Clemente Island, the southernmost of the California Channel Islands. Recently (1992), we have seen diseased abalone on San Nicolas Island (pers. obs., VanBlaricom, Ruediger, Friedman, Woodard \& Hedrick unpubl.). The only apparently unaffected island is Santa Catalina (where black abalone were

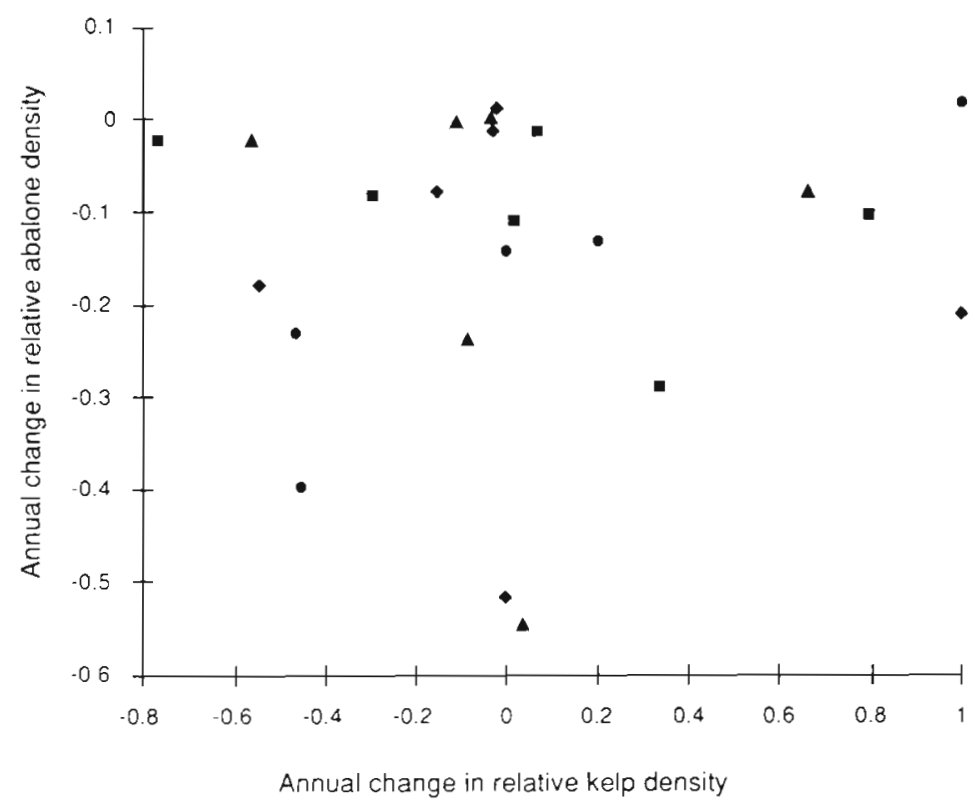

Fig. 3. Haliotis cracherodii and Macrocystis pyrifera. Changes in abalone density and changes in adult kelp density at 4 sites. $(\bullet),(\bullet) \mathrm{JL}$,

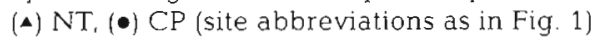




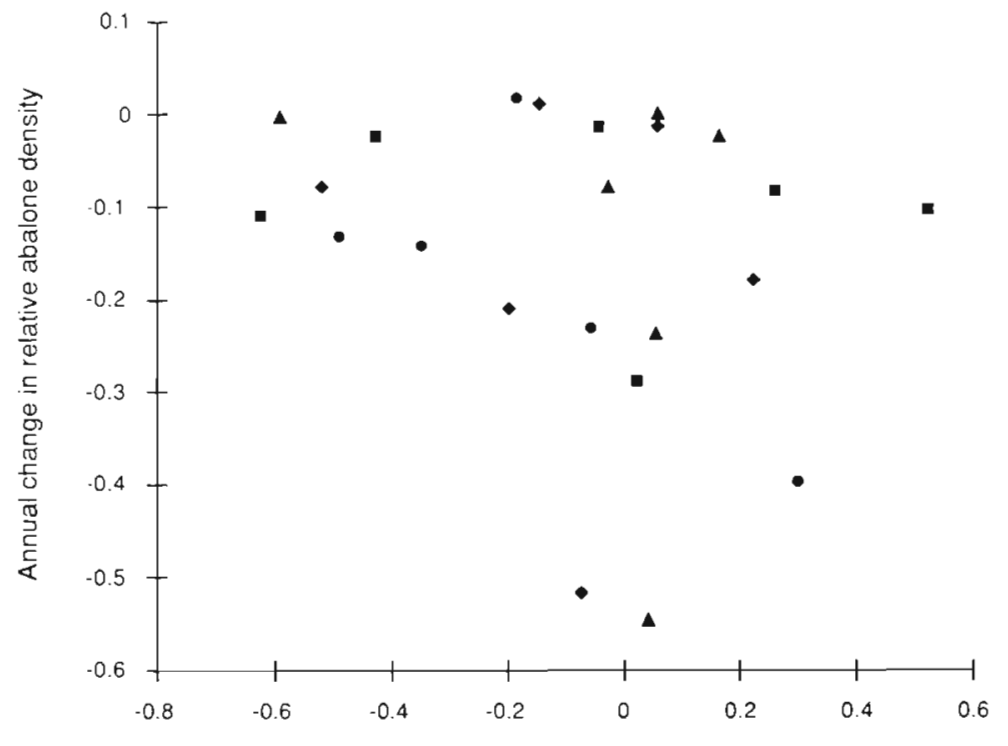

Annual change in relative urchin density

Fig. 4. Haliotis cracherodii and Strongylocentrotus spp. Changes in abalone density and changes in sea urchin density at 4 sites. $(\bullet) \mathrm{W},(\bullet) \mathrm{JL}$, $(\bullet)$ NT, $\bullet$ CP (site abbreviations as in Fig. 1) the south side of Santa Cruz Island (Fig. 6; $\log$ transformed distance, $r=0.794, \mathrm{df}=16$, $\mathrm{p}<0.01$ ). Including information from prevailing current directions strengthened the association between date and distance. We were able to improve the coefficient of the date by distance correlation from 0.698 to 0.754 (untransformed) by increasing the current 'resistance' factor to 1.5 for sites up-current from Santa Cruz. This effect is not striking but is consistent with the hypothesis that currents help spread WS. Contrary to the pollution hypothesis, we did not find any association between the rate of the die-off and distance from the south side of Santa Cruz Island, even after incorporating current patterns $(r=-0.020$, $\mathrm{df}=8, \mathrm{p}>0.05 \mathrm{j}$. Finally, contrary to the directly transmitted disease hypothesis, there was no association between mortality rate and the initial abalone density ( $\mathrm{r}=$ $-0.55, \mathrm{df}=9, \mathrm{p}>0.05$ )

\section{DISCUSSION}

never as abundant as at the other islands; P. Haaker pers. comm.). However, the Santa Catalina populations of black abalone have not been monitored.

For each site, there was a significant association between the dates of the die-offs and the distance from
Although it is possible that the commercial black abalone fishery may have negatively affected abalone densities, our analysis supports the conclusion of Haaker et al. (1992) that the fishery was not responsi-
Fig. 5. Channel Islands off the coast of southern California showing the spread of WS over time. Dated contour lines represent the spatial range of WS by year. Shaded arrows indicate direction of prevailing currents

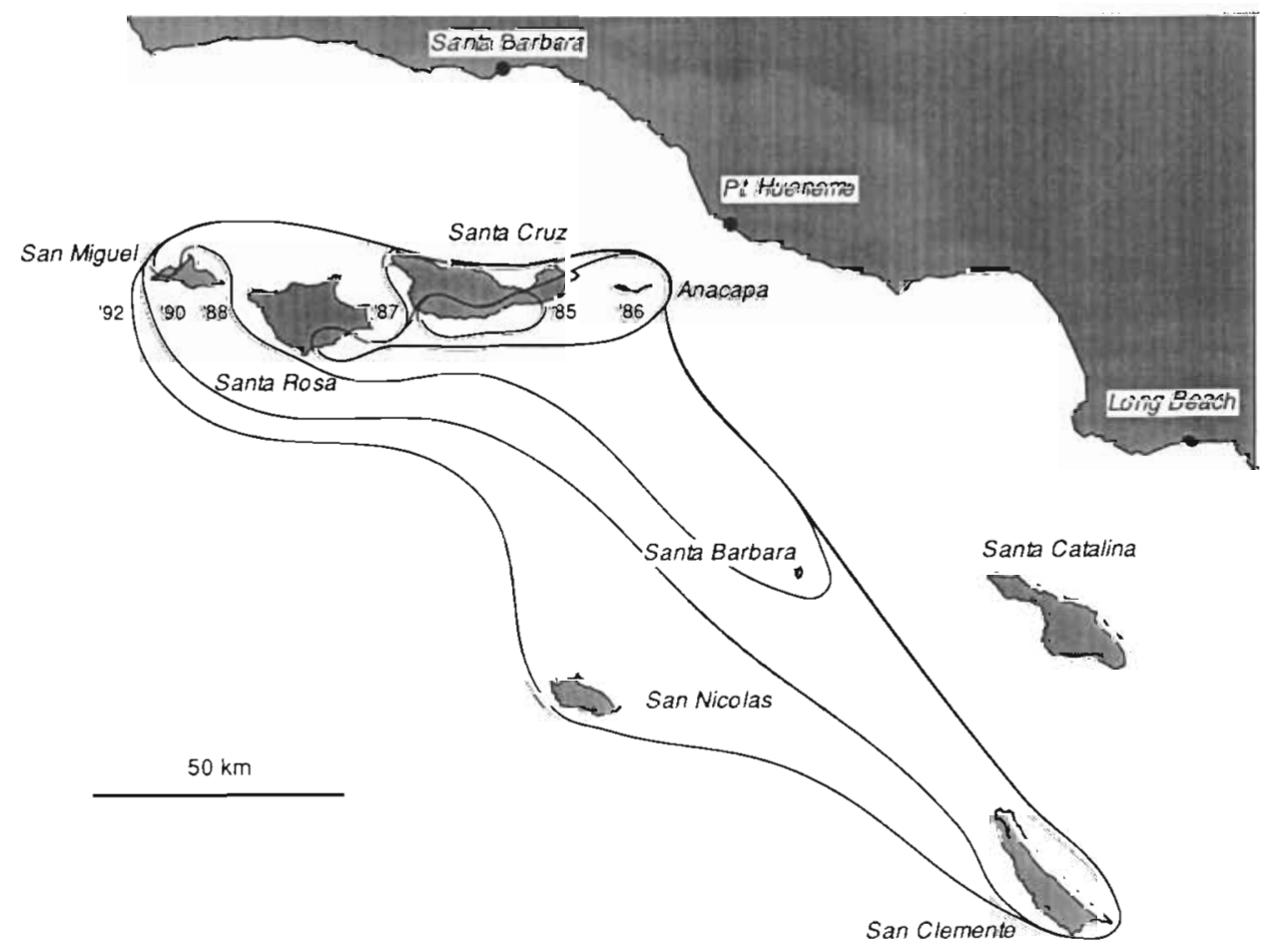




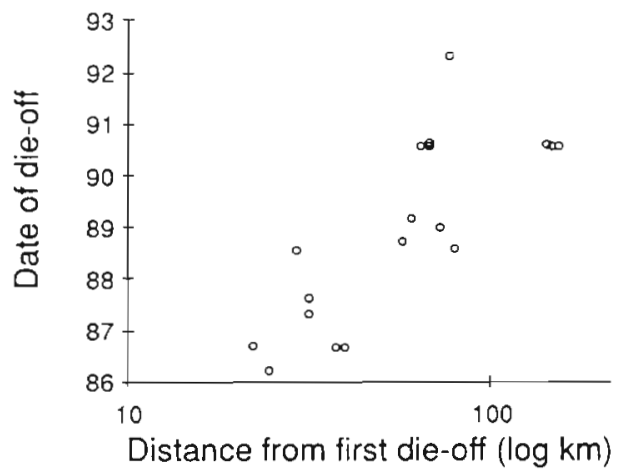

Fig. 6. Haliotis cracherodii. Date on which mass mortalities of black abalone started at various locations in the Channel Islands compared with the distance (in $\mathrm{km}$ ) of those sites from the location of the first observed die-off on the south side of Santa Cruz Island

ble for the peculiar and striking decreases in black abalone observed within the last decade. Apparently, WS has caused abalone populations to crash at site after site. The positive correlation between die-off dates and fishing intensity suggests that the fishery may have avoided areas strongly affected by WS. This disease has devastated the commercial fishery.

Although El Niño events initiated dramatic changes in the distribution and abundance of several marine species, the lack of an association between warm years, or kelp density, and the initiation of the die-offs is evidence that climatic factors are not responsible for the disease. The lack of an association between kelp density and abalone density is consistent with the observation that sick abalone do not recover when given food in the laboratory (Haaker et al. 1992). In contrast, starving abalone can recover after transplantation to areas with food (Cox 1962, Young 1964). If the 1983-84 and subsequent El Niños had been responsible for WS, die-offs would have been synchronized with, or followed, periods of warm water. Although die-offs proceeded at faster rates in warmer waters, the spread of WS to places where abalone appeared healthy and well fed, such as San Nicolas Island, suggests that physiological stress is not a required co-factor for the disease.

Our results suggest that WS has spread from a central focus and that this spread may have been aided by prevailing currents. This is the spatial pattern expected if an infectious disease or pollution caused WS. Our conclusion that a point source of pollution is not responsible for WS is consistent with other studies that have not found any differences in metals or pesticide concentrations between sick and healthy abalone (Haaker et al. 1992). In addition, sick abalone always die even when placed in clean filtered sea water
(Haaker et al. 1992). Although the sinking of a copper ore freighter, the 'Pac Baroness', provided a potential point source of pollution, this event occurred in 1988 after the start of WS. Also, the location of the event at Point Conception is seemingly inconsistent with the observed pattern of spread. Furthermore, except for the U.S. Navy's submarine listening post located at East Valley Anchorage, it is not evident that potential sources of pollution exist on the back side of Santa Cruz Island. Thus, the lack of a positive association between the dates of the die-offs and the distance from major ports, as well as the lack of a negative correlation between dates of the die-offs and fishing intensity, indicates that humans were not directly responsible for the initiation or spread of WS. An untested and more complex alternative hypothesis is that a toxic food source has spread out from the back side of Santa Cruz Island. Again, since abalone brought to the laboratory can develop the disease and do not recover, it is not likely that the disease is dietary. Finally, we have not specifically addressed the possibility that several factors have acted in concert to cause the die-off such that a single factor, when analyzed alone, does not appear to be significant. Although our data set does not lend itself to such an analysis, we have found no indication that a consideration of additive effects would alter our interpretations.

The rapid mortality at sites with warm water temperatures supports laboratory studies that show increased mortality rates at higher temperatures (Parker et al. 1992). This association with temperature is consistent with an infectious agent. However, the lack of an association between abalone density and mortality rates, combined with observations that healthy abalone do not become sick when placed in aquaria containing sick abalone (C. Friedman pers. comm.), suggests that WS is not directly transmitted between abalone. Many diseases are not directly transmitted, however, and it is possible that an intermediate host, a vector or otherwise complex life-cycle (e.g with dormant stages] is involved Unfortunately, the agent of this putative infectious disease is unidentified. Viruses and bacteria have not been detected and the pathology is not consistent with Perkinsus spp. or other known causes of abalone mortality (Haaker et al. 1992). An implicated coccidian parasite does not seem to be responsible for WS because it infects all black abalone and there is no relationship between intensity and WS pathology (Haaker et al. 1992, Kuris \& Stevens unpubl.). Recently, WS was elicited in previously healthy abalone by injecting them with hemolymph from diseased individuals (C. Friedman, Shellfish Pathologist, California Dept Fish and Game, unpubl.). This buttresses our conclusion that WS is an infectious disease. 
What will happen now that WS has passed through the Channel Islands? Other species of abalone, Haliotis rufescens and $H$. corrugata, have declined substantially in density over this time, even in areas protected from harvesting (Davis et al. 1992). Anecdotal reports of shrunken foot in these species suggest that WS might be a potential factor. However, these species occur at such low densities that a mass mortality event would be difficult to detect. Because they are drift kelp feeders, black abalone might not have large effects on intertidal community structure (Bergen 1971). However, black abalone are numerically dominant space holders in cracks and on vertical substrate in the lower intertidal zone (VanBlaricom 1993). Douros (1985) found that abalone reduce the abundance of fleshy algae while they increase the density of limpets and inedible coraline algae; areas with few abalone, on the other hand, had a high percentage cover of the encrusting vermetid snail Serpulorbis squamigerus and the colonial polychaete worm Phragmatopoma californica. The latter finding is disturbing as we have observed apparent increases in the density of these worms in areas where black abalone were formerly abundant. An alternative stable state might be developing where these space holders could act to reduce the potential for black abalone to recruit back to their former habitat. The low recruitment rates observed for black abalone (VanBlaricom 1993) reinforce this concern. On the bright side, we have observed healthy and persistent survivors of these mass mortalities. On Santa Cruz Island, where we base most of our observations, WS has not been apparent since at least 1991 and perhaps longer. The remaining populations are sparse but may represent individuals that are somehow resistant to WS. Further ecological studies will be required to make more detailed predictions about the impact of WS. At the moment, the opportunity exists to conduct a detailed small scale geographic study of WS on San Nicolas Island where the disease most recently emerged and excellent baseline information is available (VanBlaricom 1993).

Acknowledgements. We greatly appreciate Pete Haaker and Carolyn Friedman, California Department of Fish and Game, Gary Davis and Dan Richards, National Park Service, Glen VanBlaricom and Joan Ruediger, U.S. Fish and Wildlife Service and the University of California Santa Cruz, and Brian Tissot, University of Hawaii - Hilo, for generously providing us data on density changes of black abalone and other information about their studies on the Channel Islands. We also thank Pete Haaker for the detailed landings data and Shane Anderson for the University of California Santa Barbara temperature data. Additional important information was provided by John Steinbeck and Dave Sommerville (Pacific Gas \& Electric Co.), Ken Schmidt (commercial fisherman) and
Carrie Culver, Jenny Dugan, David Kushner and Theresa Stevens. We also thank Russ Schmitt, Jeffrey Shields and Theresa Stevens for their comments on the manuscript and the National Marine Sanctuary Program for their generous funding for this project. This work is partially a result of research sponsored in part by NOAA, National Sea Grant College Program, Department of Commerce, under grant number NA89AA-D-SG138, project number R/F-135, through the California Sea Grant College, and in part by the California State Resources Agency. The U.S. Government is authorized to reproduce and distribute for governmental purposes.

\section{LITERATURE CITED}

Bergen, M. (1971). Growth, feeding and movement in the black abalone, Haliotis cracherodii Leach, 1817. Master's thesis. University of California, Santa Barbara

Cox, K. W. (1960). Review of the abalone in California. Calif Fish Game 46: 381-406

Cox, K. W. (1962). California abalones, family Haliotidae Calif. Fish Game Fish Bull. 118: 1-133

Davis, G. E., Richards, D. E., Haaker, P. L., Parker, D. O. (1992). Abalone population declines and fishery management in southern California. In: Shepherd, S. A., Tegner, M. J., Gusman del Proo, S. A. (eds.) Abalone of the world: biology, fisheries and culure. Proc. 1st Int. Symp. Abalone. University Press, Cambridge, p. 237-249

DenHartog, C. (1987). 'Wasting Disease' and other dynamic phenomena in eel grass beds. Aquat. Bot. 27: 3-14

Douros, W. J. (1985). Density, growth, reproduction and recruitment in an intertidal abalone: effects of intraspecific competition and prehistoric predation. Master's thesis. University of California, Santa Barbara

Douros, W J. (1987). Stacking behavior of an intertidal abalone: an adaptive response or a consequence of space limitation? J. exp. mar. Biol. Ecol. 108: 1-14

Dungan, M. L., Miller, T E., Thompson, D. A. (1982). Catastrophic decline of a top carnivore in the Gulf of California rocky intertidal zone. Science 216: 989-991

Ebeling, A. W., Laur, D. R., Rowley, R. J. (1985). Severe storm disturbances and reversal of community structure in a southern California kelp forest. Mar. Biol. 84: 287-294

Haaker, P. L., Henderson, K. C., Parker, D. O. (1986). California abalones. California Marine Resources Leaflet 11. University of California Sea Grant Marine Advisory Program Cooperative Extension, La Jolla

Haaker, P. L., Richards, D. V., Friedman, C. S., Davis, G. E. Parker, D O., Togstad, H. A. (1992). Mass mortality and withering syndrome in black abalone, Haliotis cracherodii, in Californa. In: Shepherd, S. A., Tegner M. J., Gusman del Proo, S. A. (eds.) Abalone of the world: biology, fisheries and culture. Proc. 1st Int. Symp Abalone. University Press, Cambridge, p. 214-224

Hendershott, M. (1991). Application of observations in the Southern California Bight. In: Southern California Bight physical oceanography. Proceedings of a workshop. U.S Dept of the Interior. Minerals Management Service (MMS 91-0033), Washington, DC, p. 51-68

Ino, $T$ (1966). (The abalone science and its propagation in Japan.) Nippon Suisan Shigaen I Jogo Kyokai, Suisan Zoyoshoku Sosho 11. [Translated from Japanese in Fish Res. Bd Can. Trans. Ser. 1078 (1968)]

Johnson, J. R. (1982). An ethnohistoric study of the island Chumash. Master's thesis, University of California, Santa Barbara 
Jones, G. M., Scheibling, R. E. (1985). Paramoeba sp. (Amoebida, Paramoebidae) as the possible causative agent of sea urchin mass mortality in Nova Scotia. J. Parasitol. 71: 559-565

Leighton, D., Boolootian, R. A. (1963). Diet and growth in the black abalone, Haliotis cracherodii. Ecology 44: 227-38

Lessios, H. A. (1988). Mass mortality of Diadema antillarum in the Caribbean: what have we learned? A. Rev. Ecol. Syst. 19: $371-393$

Lester, R. J. G., Goggin, C. L., Sewel, K. B. (1988). Perkinsus olseni and other Perkinsus infections from Australian molluscs. 3rd Int. Colloq. Pathol. Mar. Aquacult., Gloucester Pt. VA

Martin, M., Stephensen, M. D., Martin, J. H. (1977), Copper toxicity experiments in relation to abalone deaths observed in a power plant's cooling waters. Calif. Fish Game 63: $95-100$

Miller, R. J., Colodey, A. G. (1983). Widespread mass mortalities of the green sea urchin in Nova Scotia, Canada. Mar. Biol. 73: 263-267

Muratto, M. J. (1984). California archeology. Academic Press, New York

O'Donoghue, P. J., Phillips, P. H., Shepherd, S. A. (1991.). Infections by Perkinsus (Protozoa: Apicomplexa) in abalone from South Australian waters. Trans. R. Soc. Aust. 115: 77-82

Parker, D. O., Haaker, P. L., Togstad, H. A. (1992). Case histories for three species of California abalone, Haliotis corrugata, $H$. fulgens and $H$. cracherodii. In: Shepherd, S. A., Tegner, M. J., Gusman del Proo, S. A. (eds.) Abalone of the world: biology, fisheries and culture. Proc 1st Int. Symp. Abalone. University Press, Cambridge, p. 384-394

Pearse, J. S., Costa, D. P., Yellin. M. B., Agegian, C. R. (1977) Localized mass mortality of red sea urchin Strongylocentrotus franciscanus, near Santa Cruz, California. Fish. BuIl. U.S. 75: 645-648

Perkins, F. O. (1976). Dermocystidium marinum infection in oysters. Mar. Fish. Rev. 38: 19-21

Resources Partnership (1974). Marine resources training project. Environmental Committee, Commission of the Californias. University of California, Los Angeles, Map \#2

Sainsbury, K. J. (1982). Population dynamics and fishery management of the paua, Haliotis iris. I. Population structure growth, reproduction, and mortality. N.Z. J. mar. freshwat. Res. 16: 147-161

Sakai, S. (1962). Ecological studies on the abalone, Haliotis discus hannai Ino. IV. Studies on the growth. Bull. Jap Soc. scient. Fish. 28: 899-904

Schmitt, R. J., Connell, J. H. (1984). Field evaluation of an abalone enhancement program. In: California Sea Grant College Program 1980-82 Biennial Report. Institute of Marine Resources, University of California, La Jolla

Shepherd, S. A., Breen, P. A. (1992). Mortality in abalone: its estimation, variability and causes. In: Shepherd, S. A. Tegner, M. J., Gusman del Proo, S. A. (eds.) Abalone of the world: biology, fisheries and culture. Proc. 1st Int. Symp. Abalone. University Press, Cambridge, p. 276-304
Steinbeck, J. R., Groff, J. M., Friedman, C. S., McDowell, T. Hedrick, R. P. (1992). Investigations into a mortality among populations of the California black abalone, Haliotis cracherodii, on the central coast of California, USA. In: Shepherd, S. A., Tegner, M. J., Gusman del Proo, S. A. (eds.) Abalone of the world: biology, fisheries and culture. Proc. 1st Int. Symp. Abalone. University Press, Cambridge, p. 203-213

Sutherland, J. P. (1974). Multiple stable points in natural communities. Am. Nat. 108: 859-873

Tanaka, K., Ishida, O., Tanaka, T. (1986). On the lost weight of abalone around Mera Shoal in the southern coast of the Boso Peninsula, Japan. I. On the distribution of abalone. Bull. Jap. Sea reg. Fish. Res. Lab. 36: 49-58

Tegner, M. J. (1980). Multispecies considerations of resource management in southern CaIifornia kelp beds. Can. tech. Rep. Fish. Aquat. Sci. 954: 125-43

Tegner, M. J (1989). The California abalone fishery: production, ecological interactions, and prospects for the future. In: Caddy, J. F. (ed.) Scientific approaches to management of invertebrate stocks. Wiley, New York, p. 401-420

Tegner, M. J., Butler, R. A. (1989). Abalone seeding. In: Hahn, K. O. (ed.) Handbook of culture of abalone and other marine gastropods. CRC Press, Boca Raton, p. 157-182

Tegner, M. J., Dayton, P. K. (1987). El Nin̄o effects on southern. California kelp forest communities. Adv. ecol. Res. 17: 243-279

Tegner, M. J., Levin, L. A. (1982). Do sea urchins and abalones compete in California kelp forest communities? In: Lawrence, J. M. (ed.) International echinoderms conference. Tampa Bay. A. A. Balkema, Rotterdam, p. $265-271$

Tegner, M. J., Levin, L. A. (1983). Spiny lobsters and sea urchins: analysis of a predator-prey interaction. J. exp. mar. Biol. Ecol. 73: 125-150

Tissot, B. N. (1988). Mass mortality of black abalone in southern California. Am. Zool. 28: 69A

Tissot, B. N. (1990). El Niño responsible for decline of black abalone off southern California. Hawaiian Shell News 38: $3-4$

VanBlaricom, G. R. (1993). Dynamics and distribution of black abalone populations at San Nicolas Island. In: Hochberg, E. G. (ed.) Recent advances in California Islands Research: Proc. Third California Islands Symp. Santa Barbara Museum of Natural History, Santa Barbara, California (in press)

VanBlaricom, G. R., Estes, J. A. (eds.) (1988). The community ecology of sea otters. Ecology Series 65. Springer-Verlag, New York

Williams, E. H. Jr, Bunkley-Wiltiams, L. (1990). Recurring mass mortalities of Caribbean herrings: implications for the study of major marme ecological disturbances. J. aquat. Anim. Health 2: 230-236

Young, P. H. (1.964). Some effects of sewer effluent on marine tife. Calif. Fish Game 50: 33-41

Manuscript first received: January 19, 1993

Revised version accepted: April 27, 1993 